\title{
Temperature-controlled Restrictor for UV Detection in Capillary Supercritical Fluid Chromatography
}

\author{
Dongjin Pyo \\ Department of Chemistry, Kangwon National University, ChunChon 200-701, Korea. "E-mail:pyod@kangwonackr \\ Received Mav 22, 2006
}

\begin{abstract}
Polyaromatic hydrocarbons were separated by a capillary supercritical fluid chromatographic (SFC) column and detected by a UV detector at the wavelength of $280 \mathrm{~nm}$. The temperature-controlled restrictor was designed for UV detection. The temperature-controlled restrictor is a $20 \mathrm{~cm}$ length of deactivated fused silica of $7 \mu \mathrm{m}$ i.d. which is held right after UV detector of the capillary SFC. The temperature of the restrictor will control the flow rate of the supercritical carbon dioxide mobile phase through the capillary column in SFC. Thus as the pressure in the column is increased from $1500 \mathrm{psi}$ to $4000 \mathrm{psi}$ during a pressure program, the temperature of $7 \mu \mathrm{m}$ fused-silica tube can be varied from 100 to $350^{\circ} \mathrm{C}$ to maintain a constant flow rate.
\end{abstract}

Key Words : Supercritical fluid chromatography, Polyaromatic hydrocarbons, Temperature-controlled restrictor

\section{Introduction}

The applicability of supercritical fluid is still expanding in the fields of not only chromatography but also extraction.' chemical reaction ${ }^{2}$ and environment. ${ }^{3}$ The advantages of supercritical fluid chromatography (SFC) have recently been recognized, ${ }^{4}$ especially capillary column supercritical fluid chromatography, although the chromatography with a supercritical fluid as mobile phase was suggested more than 40 years ago. ${ }^{5}$

In SFC, various types of detectors including the UV absorption detector, flame ionization detector (FID), fluorescence, refractive index, mass spectrometer, etc. have been used. With supercritical $\mathrm{CO}_{2}$ and several other $\mathrm{SFC}$ mobile phases, it is possible to use a UV detector. In many cases, a non-destructive type detector is favourable because it is not necessary to split and waste the effluent containing sample solutes. For this reason, a UV detector is the most feasible among the detectors, which are compatible with supercritical fluids. The UV detector generally offers a stable baseline, high sensitivity, and wide linear dynamic range even with supercritical fluids. In addition, supercritical carbon dioxide is transparent even at $190 \mathrm{~nm}$, which is the short wavelength limit of most of the commercial variable wavelength $\mathrm{UV}$ detectors.

The use of a supercritical fluid as a mobile phase requires that a flow restrictor be provided at the outlet the column in order to maintain the mobile phase above the critical pressures throughout the column. In the coupling of $100 \mu \mathrm{m}$ i.d. open-tubular SFC columns with liquid chromatography (LC)-type detectors such as the UV detector the role of the flow restrictors is to maintain the pressure and flow rate of the mobile phase throughout the column. Three types of flow restrictors are frequently used in capillary SFC: linear restrictors, ${ }^{6}$ tapered restrictors ${ }^{7}$ and integral restrictors. ${ }^{8}$

For most chromatographic experiments, it is very important to find the optimum variables, e.g., flow rate, temperature and pressure, to maximize the column efficiency. SFC is no exception. The minimum height equivalent to a theoretical plate (HETP) for separations performed with open-tubular capillary columns is approximately 0.7 times the column diameter. Novotny et al ${ }^{9}$ have shown that optimum performance in capillary $\mathrm{SFC}$ is achieved through the use of tubes with i.d. 50-100 $\mu \mathrm{m}$.

For open-tubular columns, the plate height $(\mathrm{H})$ as a function of linear velocity $(u)$ is expressed by the Golay equation: ${ }^{10}$

$$
H=B / u+C_{S i t}+C_{m} u
$$

In eqn (1), $C_{s}^{*}$ is the coefficient of mass transfer in the stationary phase and $C_{m}$ is the coefficient of mass transfer in the mobile phase. Three contributions to band broadening, axial diffusion, resistance to mass transfer in the stationary phase and resistance to mass transfer in the mobile phase, are all represented in eqn. (1), and can be expected to be present in SFC. In GC with lightly loaded partition columns, it is found that $C_{m} \gg C_{s}^{+}$to the extent that the increase in plate height due to the negligible $C_{s}^{t}$. As diffusion coefficients are smaller in a supercritical fluid than in a gas, this predominance of $C_{m}$ for a given phase ratio is even greater in $\mathrm{SFC}$, allowing the $C_{s}^{t}$ term to be dropped:

$$
H=B / u+C_{m} u
$$

In eqn (2), $B$ is the coefficient of longitudinal diffusion and is defined $B=2 D_{m}, C_{m}$ is the coefficient of mass transfer in the mobile phase and is defined $C_{m}=\left(\left(1+6 k+11 k^{2}\right) /(24(1\right.$ $\left.+k)^{2}\right) r^{2} / D m$. Using these relations, eqn (2) can be expanded as follows:

$$
H=\frac{2 D_{m}}{u}+\frac{1+6 k+11 k^{2}}{24(1+k)^{2}} \frac{r^{2}}{D_{m}} u
$$

In eqn (3), $D_{m}$ is the diffusion constant in mobile phase, $k$ is the capacity factor and $r$ is the radius of the capillary 


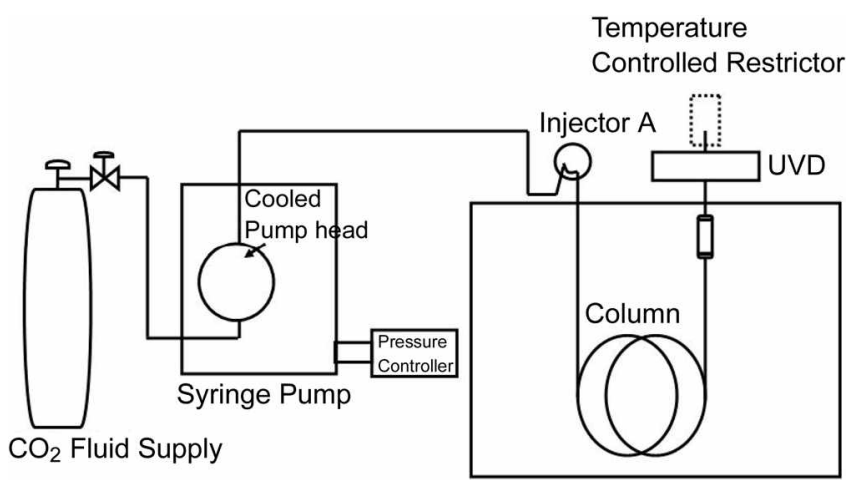

Figure 1. Schematic diagram of the capillary SFC/UVD system.

column. Eqn. (3) can be used to calculate the Van Deemter curves in most capillary SFC experiments.

The most widely used gradient technique for $\mathrm{SFC}$ is pressure gradients, where the mobile phase density is altered to increase the resolution and shorten the analysis time. By steadily increasing the average pressure in the column, relatively large molecules experience an increase in solubility. This is generally expressed as a decrease in capacity factor. This effect can be used to enhance greatly the relative molecular mass range that can be covered in a single run. As the pressure programme advances, the mobile phase flow velocity will increase as the pressure increases. It would be ideal if one could both maintain a sufficient pressure and maintain a constant linear velocity of the mobile phase during a pressure programme. One of the most effective ways to do this is to control the restrictor temperature." Increasing the restrictor temperature decreases the mass flow through capillary columns in a predictable way. Restrictor temperature programming, therefore, offers the potential for independent control of column efficiency while the pump pressure controls fluid density. "1"2 This paper demonstrate that this can be done effectively by the use of a temperaturecontrolled restrictor connected after UV detector (Fig. I). The temperature-controlled restrictor consists of a $20 \mathrm{~cm}$ length of deactivated fuse silica of $7 \mu \mathrm{m}$ i.d. held in a temperature controlled environment. As the temperature of this tubing is varied, the viscosity of the fluid passing through it also change, changing the pressure drop across the tube. The relative length, inside diameter and temperature of the tube will control the pressure differential across its length. Thus, as the pressure in the column is increased during a pressure or density programme, the temperature of the $7 \mu \mathrm{m}$ fused-silica tube can be varied to maintain a constant linear velocity of the mobile phase.

\section{Experimental Section}

A HP (Hewlett Packard, Palo Alto, CA) Model 5890 gas chromatograph was reconstructed in the laboratory as a supercritical fluid chromatograph. This system was equipped with a C14W loop injector (Valco) and a UV detector (Linear 203, Reno, NV, USA). SFC-grade carbon dioxide (Scott Specialty Gases) was used as a basic mobile phase. A
$4 \mathrm{~m} \times 100 \mu \mathrm{m}$ i.d. open-tubular capillary column with a 0.4 $\mu \mathrm{m}$ film thick layer of DB-5 (5\% diphenyl-, $95 \%$ dimethylpolysiloxane) (J \& W Scientific, Folsom, CA, USA) was used. Sample volumes of $0.06 \mathrm{~mm}^{3}$ were injected without inlet splitting with a Valco $\mathrm{Cl} 4 \mathrm{~W}$ injector. Temperaturecontrolled restrictor $(20 \mathrm{~cm} \times 7 \mu \mathrm{m} \mathrm{i.d})$ was connected with a butt-connector to the end of the UV detector.

Flow rates were measured at the end of the column using an Altech Model 7445 flow meter. This meter monitors are the mass flow rate of the gas in the range 0-50 standard cubic centimeters per minute (SCCM). The accuracy is $2 \%$ of full-scale over wide temperature and pressure ranges and the time response is 2 seconds.

\section{Results and Discussion}

First of all, we tried to calculate the Van Deemter curves for our capillary SFC system using equation (3) introduced in earlier session. Using the values $D m=1.0 \times 10^{-4} \mathrm{~cm} \mathrm{~s}^{-1}, k$ $=2$ and $r=50 \mu \mathrm{m}$, the calculated Van Deemter curve is shown in Figure 2. We used such $D m$ and $k$ vakues to estimate a rough flow velocity of mobile phase in capillary SFC system. This Van Deemter curve can be used to predict SFC experimental conditions, e.g., with a $100 \mu \mathrm{m}$ i.d. capillary column the optimum flow rate is $u=0.05 \mathrm{~cm} \mathrm{~s}^{-1}$ and the minimum plate height (HETP) is $73 \mu \mathrm{m}$. These curves illustrate the important point that in order to achieve the minimum HETP, the SFC experiments should be conducted with a very low linear flow velocity (about 0.05 $\mathrm{cm} \mathrm{s}^{-1}$ ). In reality, this is very unreasonable because the solvent peak appears $5 \mathrm{~h}$ after a sample injection when a 10 $m$ length of capillary column is used. Therefore, efficiency should be sacrificed for speed of analysis. Most capillary SFC experiments are carried out at a mobile phase velocity of $1-10 \mathrm{~cm} \mathrm{~s}^{-1}$, which is well in excess of the value required to produce the lowest plate height. This certainly causes a decrease in the number of plates; for a $10 \mathrm{~m} \times 100 \mu \mathrm{m}$ i.d. column, at an average linear velocity of $u=0.05 \mathrm{~cm} \mathrm{~s}^{-1} n=$

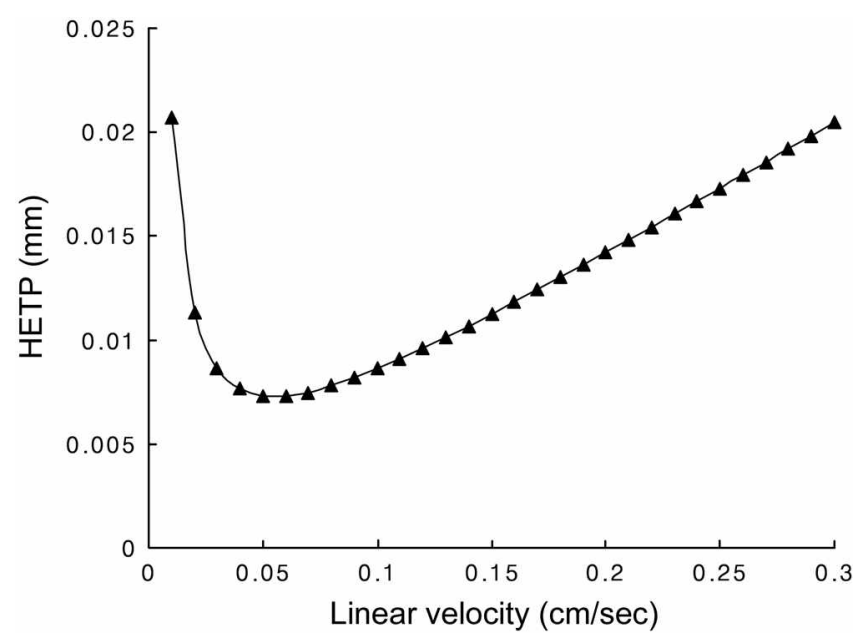

Figure 2. Van Deemter curves calculated to obtain a rough estimate of fluid velocity for capillary SFC scparations with $100 \mu \mathrm{m}$ i.d. open tubular columns $\left(D_{m}=1.0 \times 10^{-4} \mathrm{~cm} / \mathrm{scc}, k=2\right)$. 
137000 and at $u=1 \mathrm{~cm} \mathrm{~s}^{-1} n=15100$. Therefore, the average linear velocity should be maintained as near to the optimum value of a Van Deemter plot as possible.

The most elegant way of developing a temperature-programmed restrictor would be to find a series of correlations between the column flow rates and temperatures of the restrictor at various pressures. This was accomplished using the Alltech Model 7445 flow meter. The mobile phase flow velocities as a function of the temperature of the restrictor and the pressure of the column were measured using different lengths of $7 \mathrm{~mm}$ fused-silica tubes as restrictors (Fig. 3). It is demonstrated that if the temperature of the 7 $\mu \mathrm{m}$ i.d. fused-silica tubing is varied, the flow rate can be varied and can also be maintained near the optimum value of a Van Deemter curve.

In Figure 3, it is seen that when the temperature of the restrictor is increased, the flow rates are rapidly decreased. This is explained theoretically by Poiseuille's equation. In this equation, for the compressible gas, the rate of flow is

$$
\frac{\Delta V}{\Delta t}=\frac{\pi r^{4}}{16 \eta \mathrm{l}}\left(\frac{p_{i}^{2}-p_{0}^{2}}{p_{m}}\right)
$$

where $P_{i}$ is the inlet pressure, $P_{0}$ is the outlet pressure, and $P_{m}$ is the pressure at which the volume of the gas was measured. From eqn. (4), as the temperature of the restrictor is increased, the viscosity $\eta$ of the fluid is decreased, resulting in increasing mass flow rate. We just adopted eqn (4) for a rough flow rate estimate from a given pressure value.

This flow rate can be related to the mobile phase average linear velocity in a capillary SFC column. For example, for a $100 \mathrm{~mm}$ i.d. column, a gaseous carbon dioxide flow rate of $0.8 \mu \mathrm{m}^{3} \mathrm{~min}^{-1}$ corresponded to a linear velocity $\mathrm{I} \mu \mathrm{m} \mathrm{s}^{-1}$, $0.04 \mu \mathrm{m}^{3} \mathrm{~min}^{-1}$, corresponded to $0.05 \mathrm{~mm}^{3} \mathrm{~min}^{-1}$, etc.

The mixtures of four polyaromatic hydrocarbons (benzene, phenetole, naphthalene and biphenyl) were separated using capillary SFC/UV system for evaluating the feasibility of temperature-controlled restrictor described above, while the separations performed pressure programming over a

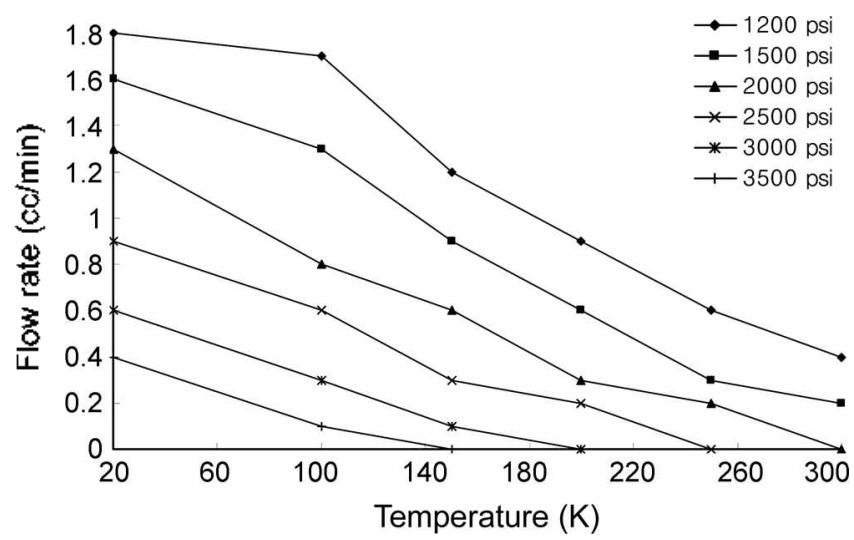

Figure 3. The flow rates as a function of temperature at various pressures of $\mathrm{CO}_{2}$ using a $100 \mu \mathrm{m}$ coluınn and a $7 \mathrm{um} \times 20 \mathrm{~cm}$ restrictor fairly wide range. The reason why UV detector is used is that polyaromatic hydrocarbons have an excellent UV absorbing functionality and supercritical carbon dioxide fluid exhibit little background absorbance at $280 \mathrm{~nm}$. Unlike the FID, which is a very nonspecific and destructive detector, the UV detector can provide compound-specific information and it is highly sensitive. For this experiment, The UV detector was tuned to $280 \mathrm{~nm}$ which is the characteristic absorption wavelength of the polyaromatic hydrocarbons. The flow through the temperature-controlled restrictor can be controlled by varying the temperature of the restrictor. As the pressure programme advances, the restriction of the temperature-controlled restrictor should be increased by increasing its temperature to keep the linear velocity of the mobile phase in the column constant.

As a control, we tried an SFC separation of four polyaromatic hydrocarbons without varying the temperature of the temperature-controlled restrictor. Figure 4 shows the chromatogram obtained. In fact, the temperature-controlled restrictor was kept at room temperature, but, the experiment was performed with pressure programming. The initial pressure was $1500 \mathrm{psi}$, increased at $125 \mathrm{psi} \mathrm{min}{ }^{-1}$ to the final pressure of $4000 \mathrm{psi}$.

Subsequently, when the temperature-controlled restrictor was tried, the resolution of the chromatogram was increased (Fig. 5). The temperature of the temperature-controlled restrictor was varied from 100 to $350^{\circ} \mathrm{C}$ to maintain the flow rate as low as possible. The capillary column used was only $4 \mathrm{~m}$ long to avoid a long analysis time and the same pressure programming as the previous experiment was used. The better resolution in Figure 5 is because a low average linear velocity was maintained by the use of the temperature-controlled restrictor.

In conclusion, at present most capillary supercritical fluid chromatograms are obtained at a linear velocity that is much higher than the optimum value on the Van Deemter curve.

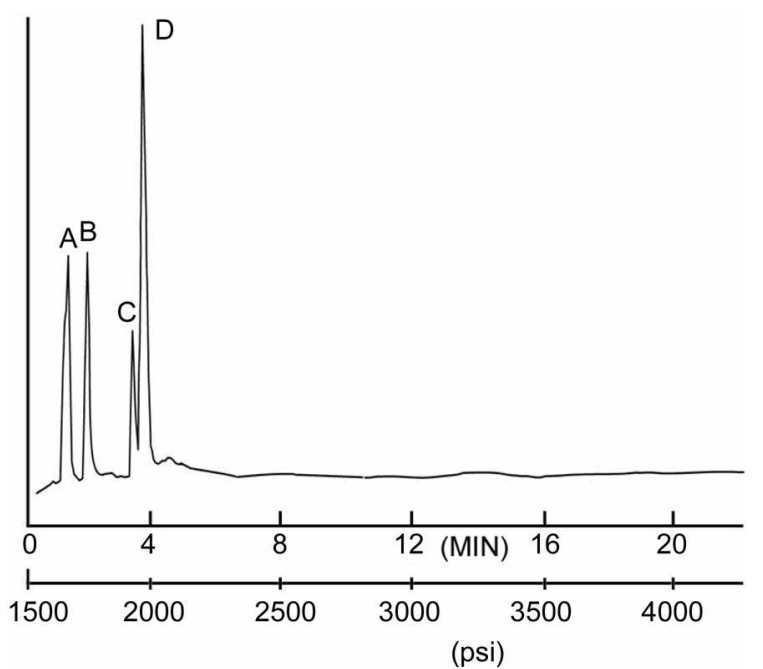

Figure 4. Supercritical fluid chromatograms of four polyaromatic hydrocarbons without controlling the temperature of the temperature-controlled restrictor. $(\Lambda=$ benzenc, $B=$ phenetole, $C=$ naphthalenc, $\mathrm{D}=$ biphenyl). 


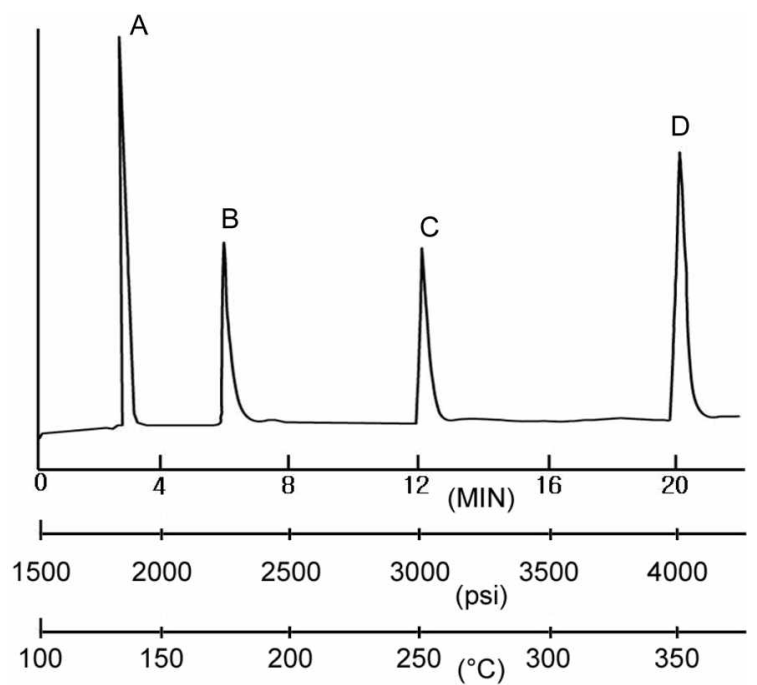

Figure 5. Supercritical fluid chromatograms of four polyaromatic hydrocabons with controlling the temperature of the temperaturecontrolled restrictor. $(\Lambda=$ benzenc, $B=$ phenctole, $C=$ naphthalene, $\mathrm{D}=$ biphenyl).

With pressure programming, the linear velocity increases still further, causing a decrease in efficiency. We have developed a temperature-controlled restrictor for SFC/UV system that can be programmed to increase the restriction during a pressure-programmed run in order that the linear velocity remains constant and the chromatographic efficiency increases.

Acknowledgement. This work was supported by a grant from Institute of Environment Research at Kangwon National University

\section{References}

I. Pyo, D.; Shin, H. Anal. Chem. 1999, 71, 4772.

2. Jessop, P. G; Ikariya, T.; Noyori, R. Science 1995, 269, 1065.

3. Sako, T.; Sugeta, T.; Otake, K.; Sato, M.; Tsugumi, M.; Hiaki, T.; Hongo, M. J. Chem. Eng. Japan 1997, Vol 30, pp 744-747.

4. Pyo, D.; Lim, C. Bull. Korean Chem. Soc, 2005, 26, 312.

5. Klesper, E.; Corwin. A. H.; Turner, D. A. J. Org. Chem. 1962, 27, 700 .

6. Kohler, J.; Rose, A.; Schomburg, G. J. High Resolut. Chromatogr. $1988,1], 191$.

7. Chester, T. L.; Innis, D. P.; Owens, G. D. Anal. Chem. 1985, 57, 2243.

8. Hawhorne, S. B.; Miller, D. J. J. Chromatogr. 1987, 403, 63.

9. Novotny, M.; Springston, S. R.; Peaden, P. A.; Fjeldsted, J. C.; Lee, M. L. Anal. Chen. 1981, 53,407.

10. Golay, M. J. E.; Desty, D. H. Gas Chronatography; Academic Press: New York, $1959 ; \mathrm{p} 36$.

11. Pyo, D, Analyst 1994, 119, 1315.

12. Berger, T. A.; Toney, C. J. Chromatogr. 1989, 465, 157. 